\title{
A STUDY OF DISCOURSE MARKERS USED IN THE THESES BACKGROUND WRITTEN BY THE STUDENTS OF ENGLISH DEPARTMENT OF BENGKULU UNIVERSITY (ACADEMIC YEAR DECEMBER 2016)
}

\author{
Dio Adewibowo \\ University of Bengkulu \\ dioade9@gmail.com \\ Imranuddin \\ University of Bengkulu \\ imranulama@gmail.com \\ Azwandi \\ University of Bengkulu \\ azwandi22@gmail.com
}

\begin{abstract}
This research was aimed at finding the types of Discourse Markers used by the students and investigating the accuracy of Discourse Markers by the students of English Education Study program graduated in December 2016 at the University of Bengkulu. This research was a descriptive study. The subjects in this research were 10 theses background from the students of English Education Study Program who graduated in December 2016. The result of this research shows that there were four types of Discourse Markers used by the students based on Bruce Fraser's theory such as Inferential markers, temporal markers, elaborative markers and contrastive markers. The most dominant marker used by the students was Inferential markers with $42 \%$. This research also found that the most accurate marker used was Temporal markers with $78.57 \%$ and the lowest accurate marker was Elaborative markers with $52.17 \%$.
\end{abstract}

Keywords : Discourse Markers, Theses Background

\section{INTRODUCTION}

Writing is something that cannot be separated from human's life, especially for those academic. Indeed, it also has a very important role in formal communication. Through writing, human can express their expressions, feelings, and thoughts for each other. According to Brown (2001) "Writing is a thinking process, because writing is a process of putting ideas down on paper to transform thought into word and give them structure and coherent organization". It means that writing always require a critical process in combining complexity of syntax, mechanics, grammar and vocabulary. Writing also becomes a part of discourse, it is called as written discourse.

For academic purpose, especially in Bengkulu University, writing a thesis as a final project has to be an obligation for students to complete their scientific project before graduating from bachelor degree. Furthermore, thesis consists of some chapters, one of them is introduction. Introduction is a part where the writers must put the reason why they do the research. As Bathia (2002) states that introduction is the key role in presenting the connection of the research 
to be reported. Moreover, the introduction of the research consists of six subchapters; they are: research background, statement of problem, objective of the research, significance of the research, scope of the research, and the definition of key term.

Generally, there are four common problems that often happened in the process of academic writing (including a thesis writing. They are content, organizing, vocabulary and grammar (Ngabo: 2003). Based on the second problem (organizing), he explained that there were three sub problems found such as the unity of the paragraph, the coherence of paragraph, and the transitions between paragraphs. So, it means that there are some writer could not organizing their written product effectively where they could not write down an effective or a good paragraph to describe the content clearly, easily, and logically to make the reader understand.

One way of organizing a good paragraph is by using discourse markers. Here, the use of discourse markers is important because discourse markers help the writers connect the idea or message through their writing. According to Nunan (1993:187) and Dulger (2007:261) "Discourse markers are words and phrase which organize, comment on, or in some way frame what we are saying or writing that function to signal how the current utterance relates to prior discourse. Besides, they help readers follow the movement of a discussion and understand the relationship between idea in the text (Harris: 2010). So, from the explanation, we could conclude that discourse markers have important role to organize the paragraph effectively, they connect the sentences like a bridge and as the result the message from the writer can be understood by the readers.
Furthermore, in conducting this research, the researcher used the thesis background from the students of English Department students study program graduated in December, 2016 to find out the purpose of the research. The reason to use the thesis background is because in writing a thesis background, people have to write it beautifully and in good organized, it means that they have to connect one sentence to another sentence as coherence as possible. Then, they also have to create a unity among the written paragraph.

Moreover, in finishing this research, the researcher used the classifications from Bruce Fraser. His classifications are suitable on this research field where the researcher try to find out the use of discourse markers on thesis background. Besides, Jalilifar (2008) stated that Fraser's classification conforms to written discourse and it seems to be the most comprehensive classification in written discourse. Bruce Frasers (1999:931) defined discourse markers as a class of lexical expressions drawn primarily from syntactic classes of conjunction, adverbs, and prepositional phrases. Fraser in his study divided discourse markers into four classes such as elaborative markers, inferential markers, temporal markers, and contrastive markers. The researcher hopes this research will give some influences for students, the lecturers, future researchers and the syllabus.

Finally, based on the problem and explanation above the researcher is interested to conduct a research about the use of discourse markers in theses background written by the sudents of English Department study program of Bengkulu University. This research also tried to find out the accuracy of discourse markers which is used by the alumni. 
This research had two research questions,

1. What are types of discourse markers used by the students of English Study Program in their thesis background?

2. How is the accuracy of discourse markers used by the students of English Study Program in their thesis background?

The researcher hopes this research will give some influences for some group of people such as, the students, the teachers or lecturers, and future researchers.

\section{METHOD}

This study is designed as descriptive research. The main goal of descriptive research is to describe the data about what is being studied. Zuriah (2007:47) claims that the descriptive research is a research that is directed to give the symptoms, facts, or events, systematically and accurate about the population characteristics or certain area.

The subjects of this research are 10 theses background from the students of English department of Universitas Bengkulu who graduated in December 2016. According to Arikunto (2006: 134) ," If the subject less than 100, it's better to take all". Based on Arikunto's opinion, the researcher takes all of 10 theses backgrounds from the Student of English Study Program of Bengkulu University which graduated at December 2016.

The instrument of this research is table of analysis based on Bruce Fraser classification of discourse markers. The function of table of analysis in this research is to classify the data (discourse markers) that exist in the source.

In this research, the first technique used is reading and identifying the theses background comprehensively and carefully by focusing on each body part of theses background. Second technique is coding the discourse markers which appeared in the theses background based on Bruce Fraser theory. The last technique is categorizing the discourse markers based on the adapted theory.

The data will be analyzed based on the discourse markers theory proposed by Bruce Fraser to get the percentage of frequency and accuracy of discourse markers used in theses background written by the students of English Department who graduated in December 2016.

This research is descriptive research that needs validation in order to achieve reliable data. The way of validating is through two scorers in analyzing the data; the researcher and coresearcher. Here, the co-researcher assists the researcher to analyze the accuracy of discourse markers used by the sample.

There will be some procedures to be followed during the research in order to find out the valid data to answer the research questions. These sequence steps of the research are:

1. Collecting theses of English Education Study Program students which graduated in December 2016 from library. The total theses were 10 theses.

2. Reading and identifying the theses background comprehensively and carefully by focusing on each body part of theses background

3. Coding the discourse markers which appeared in the theses background based on Bruce Fraser theory. 
4. Classifying the discourse markers based on the adapted theory

5. Imputing the data into table of analysis

6. Investigating the accuracy of discourse markers used.

7. After that, the researcher classifies all discourse markers into 3 groups.

Table 1. Descriptive Statistics of Frequency and Percentage

\begin{tabular}{|l|l|l|}
\hline No & Percentage & Criteria \\
\hline 1 & $80 \%-100 \%$ & High level (H) \\
\hline 2 & $50 \%-79 \%$ & Medium level (M) \\
\hline 3 & $0 \%-49 \%$ & Low level (L) \\
\hline
\end{tabular}

\section{RESULT AND DISCUSSION}

\section{Result}

\section{The Types of Discourse Markers}

The result of this research is based on the research questions. The main result of this research is expected to find out the types of discourse markers used by the students of English Study Program in writing their theses background and also to investigate the accuracy of discourse markers used by the students of English Study Program graduated in December 2016.

There are several of Discourse Markers used in the thesis background by students. According to Bruce Fraser (1996) "discourse markers are a class of lexical expressions draw premierly from syntactic class of conjunction, adverb and preposition phrases. Also, discourse markers refer to elements that connecting an utterance or sentence in discourse into a unity. The discourse markers that appeared in thesis background are classified in 4 types, they are: contrastive markers, elaborative markers, inferential markers, and temporal markers. The following table shows the types of Discourse Markers and their percentages.

Table 2. The Percentage of The Frequency of Occurences

\begin{tabular}{|c|c|c|c|}
\hline No & $\begin{array}{c}\text { Types of } \\
\text { Discourse } \\
\text { Markers }\end{array}$ & $\begin{array}{c}\text { The use of } \\
\text { Discourse } \\
\text { Markers }\end{array}$ & $\begin{array}{c}\text { Percentage } \\
(\%)\end{array}$ \\
\hline 1 & $\begin{array}{c}\text { Inferential } \\
\text { Markers }\end{array}$ & 49 & $42 \%$ \\
\hline 2 & $\begin{array}{c}\text { Temporal } \\
\text { Markers }\end{array}$ & 28 & $24 \%$ \\
\hline 3 & $\begin{array}{c}\text { Elaborative } \\
\text { Markers }\end{array}$ & 23 & $19 \%$ \\
\hline 4 & $\begin{array}{c}\text { Contrastive } \\
\text { Markers }\end{array}$ & 18 & $15 \%$ \\
\hline \multicolumn{4}{|c|}{ Total } \\
\hline
\end{tabular}

From the table above, the result shows that the type of discourse markers which is mostly used by the students in theses background is Inferential Markers. This type is used 49 times (42\% of the types of discourse markers). Followed by Temporal Markers which is used 28 times (24\%), Elaborative Markers which is used 23 times (19\%), and Contrastive Markers which is used 18 times (15\%).

The use of Inferential Markers

There are 7 inferential markers appearing in the theses background, they are so, therefore, because, consequently, hence, and in this condition. The word because is used 23 times (47\%), so is used 15 times (31\%), therefore is used 7 times (14\%), hence is used 2 times (4\%), consequently is used 1 time (2\%), and in this condition is used 1 time (2\%).

The use of Temporal Markers

The second type of Discourse markers which is mostly used by the students in writing theses background is Temporal Markers with 28 times (22\% of all type of discourse markers). They are when, meanwhile, finally, then, lastly, first, and before. The temporal markers 
used by the students are when which is used 14 times (50\%), meanwhile which is used 5 times (17.8\%), finally which is used 3 times $(10.7 \%)$, then which is used 3 times (10.7\%), lastly which is used 1 time (3.6\%), first which is used 1 time (3.6\%), and before which is used 1 time(3.6\%).

\section{The use of Elaborative Markers}

The third type of discourse markers that mostly used by the students is Elaborative Markers with 23 times (19\% of all type of discourse markers) appearing in thesis background. Elaborative Markers used by the students are moreover, for example, also, beside, and for instance. The word also is used 6 times $(26 \%)$, moreover which is used 5 times (22\%), for example which is used 5 times (22\%), beside which is used 4 times (17\%) and for instance which is used 3 times (13\%).

\section{The use of Contrastive Markers}

The last type is Contrastive Markers with 18 times (14\%). They are contrary, although, though, and but. The Contrastive Markers used by the students are but which is used 14 times (77.8\%), although which is used 2 times (11\%), though which is used 1 time (5.6\%), and contrary which is used 1 time (5.6\%).

\section{The Accuracy of Discourse Markers}

In this part, the researcher provides more specific result about discourse markers used in thesis background. Here, discourse markers are judged base on Bruse Fraser theory. In other words, the researcher analyzes how the accuracy of using discourse markers functionally in the theses background.

Generally, the researcher finds that there are 118 Discourse Markers appeared in the students' thesis background, but only 75 discourse markers are correct.

Temporal markers are the most accurate with accuracy $78.57 \%$. The amounts of correct markers are 22 of 28.
There are 7 markers used by the students in their thesis background such as when, meanwhile, finally, then, lastly, first, and before. Here, in using temporal markers, there are some errors found such as the incorrect used of punctuation among the sentences and the malfunction used of markers.

For examples:

"Those examples show the use of code mixing in social media (1). Meanwhile, the researcher chose social media Facebook as data source in order to conduct the research on code mixing (2). [106]

The sentence above is categorized as wrong because even if the punctuation is correct, it does not coherence. Besides, there is no relation that shows the explanation of time between the first statements to the second statement. For specific, the first statement talks about the examples of topic being discussed, but the second statement explains that the researcher's purpose. So, meanwhile here can not be used in this sentence. The second one is the example of the incorrect used of punctuation,

"When someone read something he/she need reading strategies to help them easier comprehend the text." [49]

The sentences above are also categorized as wrong because there is no punctuation (coma) in the middle of the sentences after the first main idea. The correct one must be:

"When someone read something, he/she need reading strategies to help them easier comprehend the text".

The second most accurate markers are Inferential markers with accuracy $61.22 \%$. The amounts of correct markers found are 30 of 49 times. The used of Inferential markers contained so, therefore, because, consequently, hence, and in this condition. Here, in using inferential markers, there are some errors 
found such as the incorrect used of punctuation and also the malfunction used of markers.

For examples:

"The writer interested to analyze the poems collection prophet because it uses figurative language. And it makes the language very beautifully and has deep meaning and also very particular interesting as media...So the writer hopes, this research can give contribution to English Language Education Study Program especially to the lecturer .... [96]

The sentence above is categorized as wrong because there is no "coma" after "so" in the beginning of the sentence. Also, the first statement is not coherence or parallel with the second statement. As can be seen in the sentences above, the first statement tells about the reason to choose the topic, but the second statement suddenly tells about the contribution of the topic. Therefore, the used of so here does not conclude what it is supposed to be.

Next, the example of the punctuation error in the used of inferential markers,

"During this period not all of the students can master English as well, because the different way or strategies in learning that learners have it means they also have different result in their learning process." [85]

Even though the sentences above is coherent, but it is categorized as wrong because there is "coma" before word "because" in the middle of the sentence. The correct one must be,

During this period, not all of the students can master English as well because the different way or strategies in learning that learners have. It means they also have different result in their learning process.

The third is Contrastive markers with the accuracy $61.11 \%$. The amounts of correct markers found are 11 of 18 times. Contrastive markers used by the students are contrary, although, though, and but. Here, there are some errors found, but the error only occurs in the used of punctuation. It means all markers are used coherently and cohesively.

For example:

"Although many publisher and the author of the textbook are claimed that their textbooks is in line with the curriculum but still there many teachers and learners confuse of it." [68]

The sentence above is wrong because there is no "coma" in the middle of sentences after the first main idea. The correct one must be,

"Although many publisher and the author of the textbook are claimed that their textbooks is in line with the curriculum, but still there many teachers and learners confuse of it".

The last one is Elaborative markers with $52.17 \%$. The amounts of correct markers found are 12 of 23 times. Elaborative Markers used by the students are moreover, for example, also, beside, and for instance. The error occurs in the used of punctuation and also malfunction used of markers.

For example:

"the first was a status from Alheru Akbar posted in December 2015 which contained of code mixing in form of phrase (last year performances) and also in form of sentence (once a family will always be a family). Besides that, the researcher also found a status from Deva Destrianti posted in December 2015 which... [99]

The incorrect used of "beside" on the sentence above occurs because the marker used is not coherence. As can be seen, the first statement uses "the first" in the beginning of sentence, but the second statement does not use "the second" in the beginning of the sentence to continue 
the same idea. The second example is the incorrect used of Discourse markers in punctuation.

"Also shakes up our imaginations as we read and helps us see the world in a new way." [93]

The sentence above is wrong because there is no coma after word "also" in the beginning of paragraph. The correct one must be,

"Also, shakes up our imaginations as we read and help us see the world in a new way."

\section{DISCUSSION}

In this research, the researcher uses Bruce Fracer's theory about Discourse markers to find the types of Discourse markers used by the students of English Education Study Program and the accuracy of discourse markers. After collecting the data, the data are classified into table analysis. Based on the analysis, there are four types of discourse markers proposed by Bruce Fraser found in the theses background. They are inferential markers, temporal markers, elaborative markers, and contrastive markers. In this research, there are 118 markers found in the theses background.

To be specific, inferential markers is the most dominant markers used by the students with frequency 49 times (42\%). The inferential markers here consist of words because, so, therefore, hence, consequently, and in this condition. Among these types of inferential markers, the highest frequency is marker because with 23 times while for the rest only occur 15 times for so, 7 times for therefore, 2 times for hence, 1 time for contrary and in this condition. This happens because inferential marker taken a big role in writing theses background in order to explain specific information about the topic being discussed.
The second is temporal markers occur 28 times (24\%) contain with words when, meanwhile, finally, then, lastly, first, and before. The result shows that marker when is being the most dominant of temporal markers used by the students. The frequency of this marker is 14 times or $50 \%$. Meanwhile, the rest only occur 5 times for, meanwhile , 3 times for finally, and then, 1 time for lastly, first, and before. All these words are categorized as chronological transition. In delivering some reason in thesis background, writers sometimes are supposed to sequence time orderly so that the readers will not be confused to catch the whole main idea of the writing.

Third, The used of elaborative markers occur 23 (19\%) times containe with words also (6), moreover (5), for example (5), beside (4), for instance (4). The most dominant marker in elaborative is marker also. It happens since in writing and oral communication, this word is always used by people in order to connect one sentence to another sentence. It adds more information about something.

The last one is contrastive markers which occur 18 times (14\%) contain with words but (14), although (2), though (1), and contrary (1). The most dominant marker is but. It happens since this word is also used in the students' writing and oral communication. It is the common way of contrasting ideas in any kind of writing. Most of the students prefer to use it possibly because it is simple, familiar, and easier to use.

Besides showing about the types of Discourse Markers used, the result also shows about the accuracy of using discourse markers. Based on the result, the most accurate marker is Temporal markers with $78.57 \%$ and the lowest accurate markers is Elaborative markers with $52.17 \%$. The errors commonly happen on the use of colon, semicolon, 
coherence, cohesion and miss understanding of the way how to use several markers such as the incorrect used of moreover, for example, also, beside, and for instance.

Compared to the previous studies, this research is different from two previous studies. In terms of objectives of the research, this research aim at finding the Discourse Markers used by the students based on Bruce Fraser theory, and investigating how the accuracy of discourse markers used in the theses background. The previous study by Mohammad Rahimi (2011) focused on investigating the frequency and the type of discourse markers used argumentative and expository writings of Iranian EFL learners and the differences between these text features in the two essay genre, and another study conducted by Hartanto (2003) at finding only the types of discourse markers.

In terms of result, this research shows that there are 4 types of discourse markers used by the students based on Bruce Fraser's classification. The most dominant marker used by the students is Inferential markers 42\%. Meanwhile, the whole accuracy of correct discourse markers on four types was $65.82 \%$ and the most accurate marker is Temporal Markers. On the other hand, the previous study by Mohamad Rahimi (2011) showed elaborative markers were the most frequently used in both argumentative and expository text. Also, the previous study conducted by Hartanto (2003) showed that the most dominant markers used by the students was inferential markers and it takes $93.19 \%$ which was correct and $6.81 \%$ was not correct.

\section{CONCLUSION AND SUGGESTION}

Based on the result of the research that is described in the previous chapter, the researcher concludes that:

1.There are 4 types of discourse markers proposed by Bruce Fraser used by the students in their theses background, namely: inferential markers, temporal markers, elaborative markers and contrastive markers. The most dominant marker used by the student is inferential markers.

2.The whole accuracy of correct Discourse markers is $63.26 \%$ which is categorized in medium level. Meanwhile, the whole accuracy of incorrect Discourse markers is $36.74 \%$. The most accurate marker used by the students is temporal markers with $78.57 \%$ which is categorized in Medium level. The lowest accurate markers was elaborative markers with $52.17 \%$.

The researcher would like to give some suggestions:

1. The students

By looking at the result which shows that the lowest acuurate marker is elaborative markers, the students are suggested to increase their understanding about it and how to use it correctly. They should use them regularly in order to get a good quality of writing.

2. The future researchers and readers

This research hopefully can be essential for any researchers who want to investigate about Discourse Markers. They are expected to do further research about factors affecting students' problem in using discourse markers. 
REFERENCES

Arikunto,S. Prosedur Penelitian : Suatu Pendekatan Praktik. Jakarta : Rineka Cipta.

Brown,H.D. 2001. Language Asessment : Principle and Classroom Practice. New York.

Fraser,B. 1999. What are Discourse Markers? Journal of Pragmatic. 31 : 931-952.
Fraser,B. $\quad 1996 . \quad$ Pragmatic Markers,Pragmatics. 6/2:167-190.

Haris, D. P. (1969). Testing english as a second language. New York: McGraw-Hill Book Company

Rahimi,M. 2011.Discourse Markers in Argumentative and Expository Writing of Iranian EFL Learners. Shiraz University. Iran. 